\title{
STUDIES OF POSSIBLE USE OF OLEIC IMIDAZOLINE AS MODIFYING AGENT FOR HARD BITUMEN
}

\author{
K. ZIELIŃSKI ${ }^{1}$, M. BABIAK ${ }^{2}$
}

Hard bitumens are used in the construction industry primarily in it's unmodified form, for instance for the production of the so-called traditional roofing felt. Due to the low price of these types of membranes, the use of a popular but expensive modifying agent, SBS copolymer, is not justified economically. Research carried out by the authors has shown that chemical organic compounds belonging to a group of imidazolines may potentially be used as much cheaper bitumen modifier. It was demonstrated that a new type of modifier based on oleic imidazoline, developed by the authors, has a significant impact on improving the physical properties of bitumen. The use of this modifier results in a significant increase in the bitumen plasticity range, both before and after laboratory ageing. In addition, there was a considerable increase of bitumen's resistance to aging. Its use can help improve the quality and durability of popular waterproofing products manufactured with the use of hard bitumen.

Keywords: hard bitumen, bitumen ageing test, oleic imidazoline

\section{INTRODUCTION}

Different varieties of "traditional" roofing membranes are most often produced using unmodified hard bitumen. Due to their moderate price they are still commonly used in construction (despite the competition of membranes produced with the use of modified bitumen).

\footnotetext{
${ }^{1}$ Poznań University of Technology, Institute of Structural Engineering, ul. Piotrowo 5, 60-965 Poznań, Poland, e-mail: krzysztof.zielinski@put.poznan.pl, (corresponding author)

${ }^{2}$ Poznań University of Technology, Institute of Structural Engineering, ul. Piotrowo 5, 60-965 Poznań, Poland, e-mail: michal.babiak@put.poznan.pl
} 
One of the main factors affecting the durability of waterproofing products manufactured with the use of hard bitumen is their resistance to ageing. Bitumen is an organic substance, susceptible to the destructive influence of atmospheric factors, primarily infrared and ultraviolet solar radiation. In order to improve the ageing resistance, bitumens used in construction are often modified in various ways. Currently, the most frequently used bitumen modifier is styrene-butadiene-styrene (SBS) copolymer. However, it has many disadvantages. It modifies the bitumen only in a physical way and it is expensive. Its cost, in the case of highly modified membranes, is nearly $30 \%$ of the material costs. Bitumen modification with SBS requires specialized equipment and is quite troublesome. SBS also significantly reduces the adhesion of bitumen to substrate, which limits the scope of ap-plications of bitumen modified with SBS. Due to the favourable group composition of soft bitumens (high oil fraction content) SBS is perfectly suitable for their modification. In the case of hard bitumen the efficiency of SBS as a modifier is quite low. The imperfection of SBS has become a strong stimulus to search for new materials that can modify hard bitumen.

Preliminary studies carried out by the authors have shown that organic compounds belonging to the group of imidazolines can be a potential bitumen modifier. The article presents the laboratory test results on the impact of one of the imidazoline varieties on slowing down the ageing processes occurring in hard bitumen.

\section{MECHANISM OF IMIDAZOLINE IMPACT AS BITUMEN MODIFIER}

Imidazolines are classified as heterocyclic compounds. They consist of a five-membered ring in which two nitrogen atoms are placed [1]. Their structure contains a ring of 4.5-dihydro- $1 \mathrm{H}-$ imidazol [2]. Imidazolines have dispersing properties and they prevent flocculation. This results in a change of thermoplastic parameters of bitumen. The reaction between imidazoline and bitumen causes blocking the processes of cyclization of aromatic compounds as well as blocking the conversion of naphtenoaromatic fractions to resins, and resins to asphaltenes.

The primary objective of the study was to determine the effect of adding imidazoline to selected physical properties of hard bitumen, most importantly its usefulness as an ageing inhibitor. Additionally, an attempt was made to optimize the content of imidazoline in bitumen to obtain the max-imum effect of impairing the ageing process.

Preliminary studies were carried out using six different varieties of imidazolines as a modifier. Each of the substances had a different chemical structure and a different fatty compound attached (lard, rapeseed oil or oleic). Each modifier was a mixture composed of two different imidazolines with 
an addition of amidoamines and alkylamines. The precise composition and proportions of the modifiers developed by the authors are protected by patents.

The studies carried out by the authors of the article have shown that the most promising effects of bitumen modification, specifically the reduction of ageing intensity, were obtained using one of the mixtures containing oleic imidazoline. It is referred to as "modifier A" in the article.

\section{BITUMEN AGEING}

The term "ageing" is defined as the changes which occur over time in the composition and chemical structure of bitumen. These changes lead to an increase of its hardness and brittleness. There are two stages of bitumen ageing $[3,4,5]$ :

- Short-term ageing, also referred to as technological ageing; takes place during the production and installation of waterproofing materials; bitumen is subjected to a short-term impact of high temperature.

- Long-term ageing, also referred to as in-use ageing; in roofing materials, climatic conditions have a direct influence on the process; mainly evaporation of volatile compounds from bitumen, and more often in particular ring compounds caused by infrared radiation and cyclization of hydrocarbons due to the impact of high-energy ultraviolet radiation.

Bitumen ageing time is difficult to determine clearly as it is dependent on the type and grade of the binder used and the conditions for its use. For example, in the case of roofing made of the traditional membrane manufactured with the use of hard bitumen, its durability without maintenance in a mild climate zone can be estimated to reach approx. 4-5 years.

\section{METHODOLOGY OF THE STUDIES}

The studies comprised the analysis of hard bitumen 95/35 samples. It is bitumen of the sol-gel type. Bitumens of this type have a quite sophisticated network structure of asphaltenes which are stabilized by a thick resin coating. This bitumen, due to it is favourable group composition (for example high asphaltene content and relatively low bitumen oil content) is hard to modify with polymers. That is why it is mainly used for the production of traditional roofing felt produced with the use of non-modified bitumen.

The modified bitumen used for the studies was a mixture developed by the authors containing oleic imidazoline (modifier A), in a concentration of $0.5 \%$ to $5 \%$ by mass of the mixture. Imidazoline 
content was increased gradually by $0.5 \%$ for concentrations of $0.5 \%$ to $3 \%$, and by $1 \%$ for higher concentrations. The scope of bitumen modification with imidazoline was estimated on the basis of preliminary studies.

Samples for testing were prepared by mixing bitumen heated to the temperature $40^{\circ} \mathrm{C}$ higher than the bitumen softening point with the addition of imidazoline. Next, for approx. 25 minutes (until a homogeneous mixture was obtained) the resulting product was stirred at the temperature of about $20^{\circ} \mathrm{C}$ higher than the bitumen softening point.

The bitumen samples ("pure" bitumen and bitumen modified with oleic imidazoline) were subjected to the following tests:

- Determination of the breaking point by Fraass method [6].

- Measurement of the softening point by Ring and Ball [7].

- Dynamic viscosity measurement using a dynamic shear rheometer DSR type MCR 101 at the temperature of $60^{\circ} \mathrm{C}[8]$.

For all imidazoline concentrations in bitumen, the above mentioned tests were performed before and after ageing with the RTFOT method [9]. This method, according to the authors, properly simulates the actual ageing of the roofing membrane [10]. In order to evaluate the ageing resistance of bitumen, the plasticity range (PR) and the ageing index (AI) were calculated. The plasticity range in which bitumen occurs as a viscoelastic material, characterized by a structural viscosity, was calculated using the following formula:

$$
\mathrm{PR}=T_{\mathrm{R} \& \mathrm{~B}}+\left|T_{\mathrm{Fr}}\right|\left({ }^{\circ} \mathrm{C}\right)
$$

For the calculation of the ageing index (AI) [3, 6] the results of the dynamic viscosity of bitumen samples were used (at temperature of $60^{\circ} \mathrm{C}$ before and after ageing). It was calculated using the formula:

$$
\mathrm{AI}=\frac{\eta_{\text {after_RTFOT }}}{\eta_{\text {before_RTFOT }}}
$$

\section{RESULTS OF THE STUDIES}

The results obtained for the softening point tests $\left(T_{R \& B}\right)$ on bitumen samples are presented in Table 1 and Figure 1. These results are the arithmetic mean of ten measurements. As it can be observed, the addition of "modifier A" leads to a fairly significant increase of the softening point in the range of its contents up to approx. 2-2,5\%. A further increase of the modifier content causes a slight but 
clear decrease of the softening point. This applies both to bitumen before and after RTFOT ageing. The minimum imidazoline content which gives the highest increase of $\mathrm{T}_{\mathrm{R} \& \mathrm{~B}}$ is approx. $2 \%$ (an increase of $11,4^{\circ} \mathrm{C}$ versus "pure" bitumen). $\mathrm{T}_{\mathrm{R} \& \mathrm{~B}}$ increase in bitumen samples tested after ageing $\left(\Delta \mathrm{T}_{\mathrm{R} \& \mathrm{~B}}\right)$ for the whole range of "modifier $\mathrm{A}$ " concentrations ranges from $5,4^{\circ} \mathrm{C}$ to $8,9^{\circ} \mathrm{C}$ and totals $7,5 \pm 0,8^{\circ} \mathrm{C}$ on average.

Table 1. Measurements of softening point by the Ring and Ball method for bitumen 95/35 and its modified varieties with ,modifier A” addition before and after RTFOT ageing

\begin{tabular}{|c|c|c|c|c|c|}
\hline Item & $\begin{array}{c}\text { Modifier content } \\
(\%)\end{array}$ & $\begin{array}{c}\mathrm{T}_{\mathrm{R} \& \mathrm{~B}} \text { before } \\
\text { ageing } \\
\left({ }^{\circ} \mathrm{C}\right)\end{array}$ & $\begin{array}{c}\mathrm{T}_{\mathrm{R} \& \mathrm{~B}} \text { increase vs. } \\
\text {,pure” bitumen } \\
\left({ }^{\circ} \mathrm{C}\right)\end{array}$ & $\begin{array}{c}\mathrm{T}_{\mathrm{R} \& \mathrm{~B}} \text { after } \\
\text { ageing } \\
\left({ }^{\circ} \mathrm{C}\right)\end{array}$ & $\begin{array}{c}\Delta \mathrm{T}_{\mathrm{R} B \mathrm{~B}} \text { (before } \\
\text { and after ageing) } \\
\left({ }^{\circ} \mathrm{C}\right)\end{array}$ \\
\hline 1 & 0,0 & $98,1 \pm 1,0$ & 0 & $105,8 \pm 0,8$ & 7,7 \\
\hline 2 & 0,5 & $99,3 \pm 1,6$ & 1,2 & $106,6 \pm 1,2$ & 7,3 \\
\hline 3 & 1,0 & $104,0 \pm 1,8$ & 5,9 & $112,1 \pm 1,7$ & 8,1 \\
\hline 4 & 1,5 & $107,4 \pm 1,2$ & 9,3 & $116,3 \pm 1,3$ & 8,9 \\
\hline 5 & 2,0 & $109,5 \pm 1,0$ & 11,4 & $117,8 \pm 1,5$ & 8,3 \\
\hline 6 & 2,5 & $109,3 \pm 0,9$ & 11,2 & $116,1 \pm 1,5$ & 6,8 \\
\hline 7 & 3,0 & $107,9 \pm 1,0$ & 9,8 & $115,0 \pm 1,3$ & 7,1 \\
\hline 8 & 4,0 & $107,4 \pm 1,0$ & 9,3 & $114,4 \pm 1,2$ & 7,0 \\
\hline 9 & 5,0 & $107,4 \pm 1,0$ & 9,3 & $113,8 \pm 1,2$ & 6,4 \\
\hline
\end{tabular}

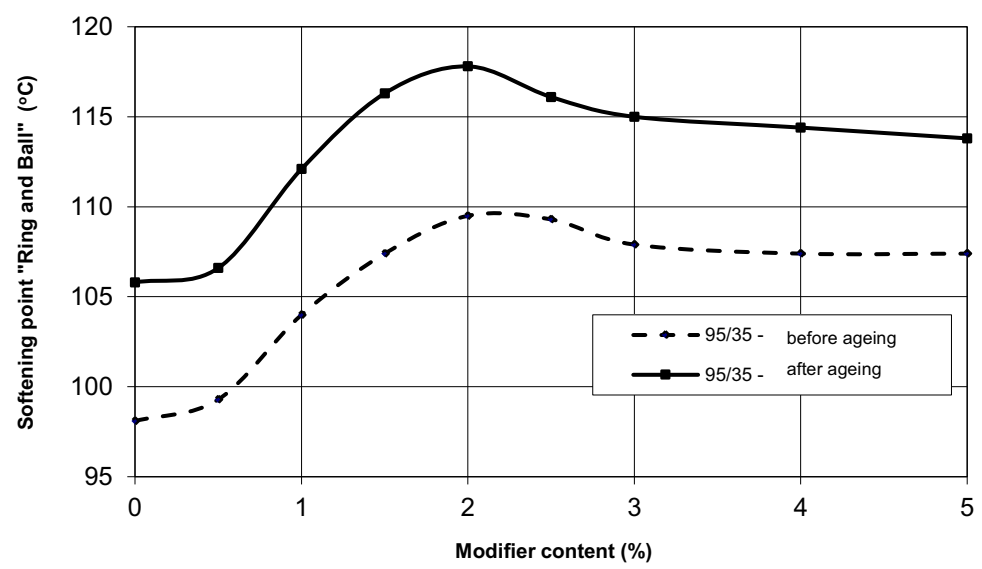

Fig. 1. Graphical presentation of softening point by Ring and Ball for bitumen 95/35 and its varieties with addition of „modifier A” before and after RTFOT for the data from Table 1 
Table 2 and Fig 2 presents the results of breaking point $\mathrm{T}_{\mathrm{Fr}}$ obtained for the prepared bitumen samples. The results provided are the arithmetic mean of ten measurements. As it can be observed, the effect of adding "modifier A" to bitumen is a linear decrease of the breaking point in bitumen, proportionate to the modifier content, both before and after RTFOT ageing.

The obtained test results are presented in the form of function $y=a x+b$. For bitumen both before and after ageing a correlation coefficient totalling 0,989 was achieved. For 9 measurements,

Table 2. Values of breaking point by Fraass for bitumen 95/35 and its varieties with the addition of ,modifier A” before and after RTFOT ageing.

\begin{tabular}{|c|c|c|c|c|}
\hline Item & $\begin{array}{c}\text { Modifier content } \\
(\%)\end{array}$ & $\begin{array}{c}\mathrm{T}_{\mathrm{Fr}} \text { before ageing } \\
\left({ }^{\circ} \mathrm{C}\right)\end{array}$ & $\begin{array}{c}\mathrm{T}_{\mathrm{Fr}} \text { after ageing } \\
\left({ }^{\circ} \mathrm{C}\right)\end{array}$ & $\begin{array}{c}\Delta \mathrm{T}_{\mathrm{Fr}} \text { (before and after ageing) } \\
\left({ }^{\circ} \mathrm{C}\right)\end{array}$ \\
\hline 1 & 0,0 & $-25,0 \pm 0,8$ & $-22,8 \pm 0,8$ & 2,2 \\
\hline 2 & 0,5 & $-25,4 \pm 0,7$ & $-23,6 \pm 1,0$ & 1,8 \\
\hline 3 & 1,0 & $-26,4 \pm 0,7$ & $-24,6 \pm 1,0$ & 1,8 \\
\hline 4 & 1,5 & $-27,4 \pm 0,7$ & $-25,6 \pm 1,0$ & 1,8 \\
\hline 5 & 2,0 & $-28,4 \pm 0,7$ & $-26,6 \pm 1,0$ & 1,8 \\
\hline 6 & 2,5 & $-29,4 \pm 0,7$ & $-27,6 \pm 1,0$ & 1,8 \\
\hline 7 & 3,0 & $-30,4 \pm 0,7$ & $-28,6 \pm 1,0$ & 1,8 \\
\hline 8 & 4,0 & $-31,4 \pm 0,7$ & $-29,6 \pm 1,0$ & 1,8 \\
\hline 9 & 5,0 & $-32,4 \pm 0,7$ & $-30,6 \pm 1,0$ & \\
\hline
\end{tabular}

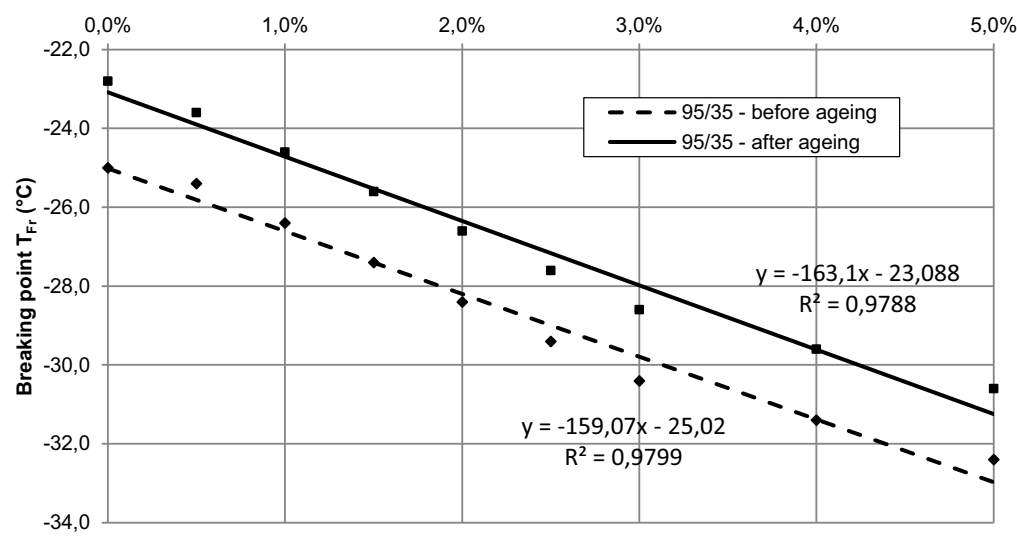

Modifier content (\%)

Fig. 2. Graphical presentation of Fraass breaking point for bitumen 95/35 and its varieties with addition of ,modifier A” before and after ageing by RTFOT for the data presented in Table 2 
The number of the degrees of freedom is $n-2=7$. For 7 degrees of freedom and the significance level of 0,05 , the critical value of the correlation coefficient is 0,6664 . It can therefore be concluded that between $\mathrm{T}_{\mathrm{Fr}}$ values and imidazoline content in bitumen there is a correlation which is linear and the addition of $1 \%$ of the modifier results in a decrease of the breaking point $\mathrm{T}_{\mathrm{Fr}}$ by approx. $1,6^{\circ} \mathrm{C}$ for bitumen both before and after ageing. In general, the ageing process of bitumen samples results in the increase of breaking point $\mathrm{T}_{\mathrm{Fr}}$. For samples of "pure" bitumen this increase totals $2,2^{\circ} \mathrm{C}$ and for the remaining samples (independently of the modifier content) it is $1,8^{\circ} \mathrm{C}$.

Table 3. Plasticity range (PR) for bitumen 95/35 modified with „modifier A” before and after RTFOT ageing

\begin{tabular}{|c|c|c|c|c|}
\hline Item & $\begin{array}{c}\text { Modifier content } \\
(\%)\end{array}$ & $\begin{array}{c}\text { PR before ageing } \\
\left({ }^{\circ} \mathrm{C}\right)\end{array}$ & $\begin{array}{c}\text { PR after ageing } \\
\left({ }^{\circ} \mathrm{C}\right)\end{array}$ & $\begin{array}{c}\text { Plasticity range increase } \Delta \text { PR } \\
\text { before and after ageing } \\
\left({ }^{\circ} \mathrm{C}\right)\end{array}$ \\
\hline 1 & 0,0 & $123,1 \pm 1,7$ & $127,0 \pm 1,3$ & 3,9 \\
\hline 2 & 0,5 & $124,7 \pm 1,9$ & $130,2 \pm 1,4$ & 5,5 \\
\hline 3 & 1,0 & $130,4 \pm 1,7$ & $136,7 \pm 2,1$ & 6,3 \\
\hline 4 & 1,5 & $134,8 \pm 1,4$ & $141,9 \pm 1,7$ & 7,1 \\
\hline 5 & 2,0 & $137,9 \pm 1,2$ & $144,4 \pm 2,0$ & 6,5 \\
\hline 6 & 2,5 & $138,7 \pm 1,2$ & $143,7 \pm 1,7$ & 5,0 \\
\hline 7 & 3,0 & $138,3 \pm 1,1$ & $143,6 \pm 1,5$ & 5,3 \\
\hline 8 & 4,0 & $138,8 \pm 1,5$ & $144,0 \pm 1,2$ & 5,2 \\
\hline 9 & 5,0 & $139,8 \pm 1,5$ & $144,4 \pm 1,6$ & 4,6 \\
\hline
\end{tabular}

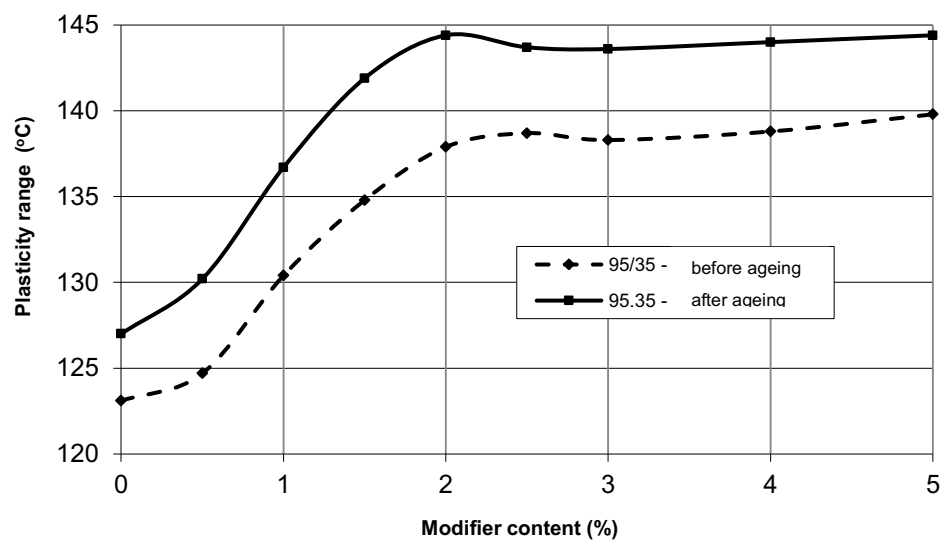

Fig. 3. Graphical presentation of the plasticity range (PR) for bitumen 95/35 modified with ,modifier A” before and after RTFOT ageing for the data presented in table 3 
Table 3 and Figure 3 present the plasticity range before and after RTFOT ageing for the bitumen samples tested, calculated on the basis of the data included in tables 1 and 2 . The values of the plasticity range increase $(\Delta \mathrm{PR})$ were also calculated for each individual bitumen sample after ageing. The plasticity range (PR) for the samples, both before and after ageing, undergoes gradual widening which is proportionate to the "modifier A" content.

The most intense widening of the plasticity range (by approx. 13\%) occurs when the "modifier A" content increases up to $2,5 \%$ (Fig. 3). A further increase of the modifier content results in only a slight widening of the plasticity range $(P R)$. The increase of the plasticity range $(\triangle P R)$ after ageing is highest $\left(7,1^{\circ} \mathrm{C}\right)$ for the "modifier $\mathrm{A}$ " content, totalling $1,5 \%$ in the bitumen tested (Fig. 4 ). When increasing the content of the modifier in the bitumen sample, initially the plasticity range gradually increases (up to $1,5 \%$ content) and next it gradually narrows down.

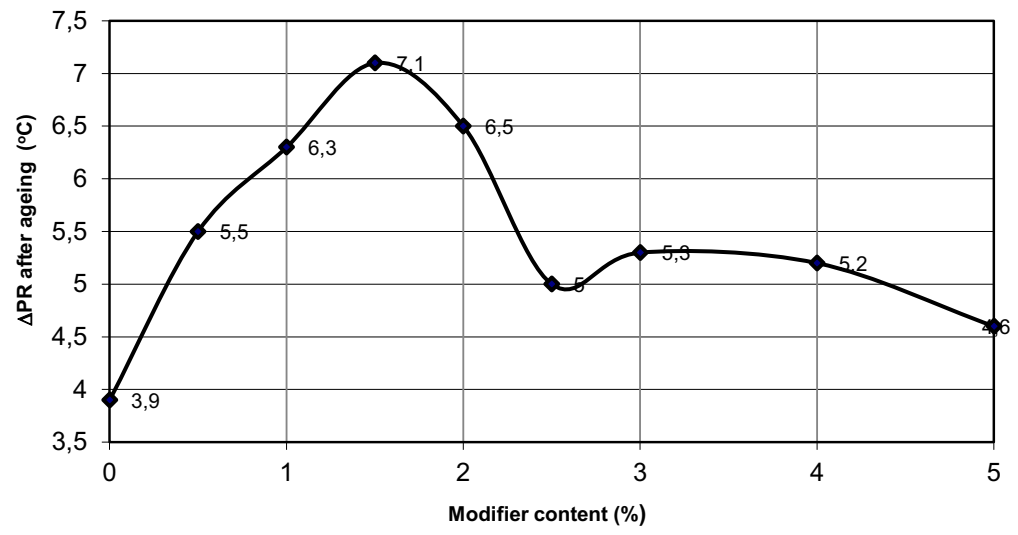

Fig. 4. Dependence between the increase of plasticity range $(\triangle \mathrm{PR})$ after ageing and ,modifier A” content in bitumen 95/35 (for data from table 3)

Table 4 and Figure 4 present the results of viscosity for the bitumen samples before and after RTFOT technological ageing. In addition, the ageing index (AI) of the bitumen was calculated (Table 4). The lowest value of the ageing index is obtained for imidazoline content equalling $1.5 \%$. For "pure" bitumen the viscosity of bitumen increases after ageing by approx. $145 \%$ and for bitumen modified with $1,5 \%$ modifier content it increases by approx. $105 \%$. 
Table 4. Dynamic viscosity values and the ageing rate for bitumen 95/35 and bitumen varieties modified with ,modifier A” before and after RTFOT ageing

\begin{tabular}{|c|c|c|c|c|}
\hline \multirow{2}{*}{ Item } & \multirow{2}{*}{$\begin{array}{c}\text { Modifier content } \\
(\%)\end{array}$} & \multicolumn{2}{|c|}{ Viscosity $(\mathrm{Pa} \times \mathrm{s})$} & \multirow{2}{*}{ Ageing index (AI) } \\
\cline { 3 - 5 } & & Before ageing & After ageing & \\
\hline 1 & 0,0 & 2018,4 & 4918,6 & $2,44 \pm 0,002$ \\
\hline 2 & 0,5 & 1846,7 & 3916,2 & $2,12 \pm 0,002$ \\
\hline 3 & 1,0 & 1727,0 & 3579,7 & $2,07 \pm 0,003$ \\
\hline 4 & 1,5 & 1675,6 & 3445,6 & $2,06 \pm 0,012$ \\
\hline 5 & 2,0 & 1642,0 & 3417,9 & $2,08 \pm 0,012$ \\
\hline 6 & 2,5 & 1622,2 & 3390,3 & $2,09 \pm 0,012$ \\
\hline 7 & 3,0 & 1601,4 & 3362,6 & $2,10 \pm 0,012$ \\
\hline 8 & 4,0 & 1586,6 & 3331,8 & $2,10 \pm 0,012$ \\
\hline 9 & 5,0 & 1574,7 & 3340,6 & $2,12 \pm 0,013$ \\
\hline
\end{tabular}

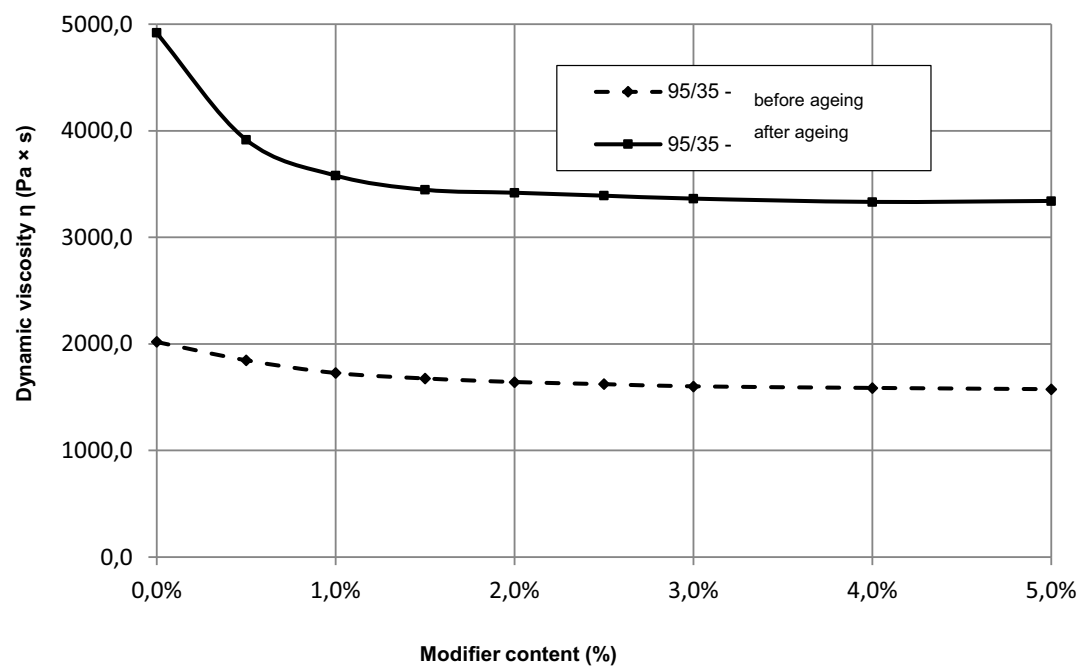

Fig. 5. Graphical presentation of dynamic viscosity for bitumen 95/35 and its varieties modified with „modifier A” before and after RTFOT ageing for data presented in table 4 


\section{ANALYSIS OF TEST RESULTS}

By analysing the study results presented in chapter 5, it may be observed that the mixture based on oleic imidazoline ("modifier A"), developed by the authors of this article, has a clear modifying impact on bitumen. It was observed that:

- The addition of $2 \%$ of the modifier increases $\mathrm{T}_{\mathrm{R} \& \mathrm{~B}}$ by $11,4^{\circ} \mathrm{C}$.

- The dependence between modifier content and the breaking point has a linear character. The addition of the modifier results in the decrease of the breaking point $\left(\mathrm{T}_{\mathrm{Fr}}\right)$ for bitumen both before and after ageing, on average by approx. $1,6^{\circ} \mathrm{C} / 1 \%$ of the modifier.

- The addition of $2,5 \%$ of the modifier results in a widening of the plasticity range by approx. $13 \%$.

- The ageing index (AI) achieves the lowest value for the modifier content totalling $1,5 \%$ (bitumen viscosity increases by approx. $1 / 3$ less than for "pure" bitumen).

In order to determine the optimum content of "modifier A" in bitumen 95/35, in Table 5, the most important modifying effects are summarised. The main parameter determining the optimum amount of bitumen modifier is the ageing rate. The lowest value is obtained for the "modifier $\mathrm{A}$ " content equalling $1,5 \%$. However, due to the beneficial effect on increasing the softening point and reducing the breaking point, therefore also expanding the plasticity range, the optimum amount of "modifier A" in hard bitumen type 95/35 is estimated to be $2,0 \%$.

The determination of the optimum content of "modifier A" allowed for a comparative analysis of the intensity of its impact with the impact it has on the most frequently used modifier - SBS copolymer.

Table 5. Analysis of study results achieved with focus on optimisation of „modifier A” content in bitumen $95 / 35$

\begin{tabular}{|c|c|c|}
\hline Type of study & $\begin{array}{c}\text { Optimum content of "modifier } \\
\text { A" }\end{array}$ & Optimum range \\
\hline Softening point ( $\left.\mathrm{T}_{\text {R\&B }}\right)$ & $2,0 \%$ & $2,0-2,5$ \\
\hline Plasticity range (PR) & $1,5 \%$ & $1,0-2,0$ \\
\hline Ageing index (AI) & $1,5 \%$ & $1,0-1,5$ \\
\hline
\end{tabular}


According to the data contained in [5], for bitumen 95/35 the optimum content of SBS modifier (linear type - Kraton D 1101) is 3\%. The modifying impact of SBS on bitumen has mainly physical character. The addition of $3 \%$ of SBS practically absorbs the entire oil phase included in the bitumen. An increase of SBS content in bitumen above 3\% virtually gives no additional effect. The comparison of modifying efficiency of SBS [5] and the "modifier A" is presented in Table 6.

Table 6. Comparison of intensity of modifying impact of SBS and „modifier A”

(at optimum content) on hard bitumen 95/35

\begin{tabular}{|c|c|c|}
\hline Type of study & $2 \%$ of "modifier A" content & $3 \%$ of SBS content \\
\hline$\Delta \mathrm{T}_{\mathrm{R} \& \mathrm{~B}}$ & $11,6^{\circ} \mathrm{C}$ & $22,5^{\circ} \mathrm{C}$ \\
\hline$\Delta \mathrm{T}_{\mathrm{Fr}}$ & $-9,4^{\circ} \mathrm{C}$ & $-13,6^{\circ} \mathrm{C}$ \\
\hline Plasticity range (PR) & $12,0^{\circ} \mathrm{C}$ & $15,5^{\circ} \mathrm{C}$ \\
\hline
\end{tabular}

As it can be seen (Table 6) for each parameter analysed 3\% of SBS content modifies bitumen to a clearly higher extent than "modifier A". However, the following should be remembered:

- the modifying effect of oleic imidazoline contained in the "modifier A" has, in practice, exclusively chemical character, therefore it is more durable than the physical impact of SBS.

- the price of both analyzed modifiers is very important. Imidazoline is a few times cheaper than SBS.

- the procedure of bitumen modification with imidazoline is much simpler (and therefore cheaper) than the modification with SBS.

In conclusion, the modifying impact of SBS copolymer on bitumen is much more intense than the impact of „modifier A”. However, the ease of use and low price make the "modifier A" an attractive alternative for the modifying substances used up-to-date.

\section{CONCLUSIONS}

Analysis of the study results demonstrated that the optimum content of properly prepared oleic imidazoline may be an effective and cheap bitumen modifier. The optimum content of the modifier tested in hard bitumen $95 / 35$ is $2 \%$. A significant impact of bitumen modification 
with the substance of a new type was observed on the improvement of its physical characteristics such as:

- a significant increase of resistance to bitumen ageing.

- an increase of the softening point temperature $\left(\mathrm{T}_{\mathrm{R} \& \mathrm{~B}}\right)$ with simultaneous decrease of the breaking point $\left(\mathrm{T}_{\mathrm{Fr}}\right)$, which is connected to a considerable increase of the plasticity range of bitumen, both before and after laboratory ageing).

The results of hard bitumen modified with oleic imidazoline "modifier A", presented in this article, are very promising. It is cheap and its optimum content in bitumen is low.

At present hard bitumen is used mainly in its unmodified form for the production of the so-called traditional roofing felts. Their durability, due to difficult in-use conditions (most frequently it is the top layer of the roofing), is relatively weak. Due to a low price of this type of roofing membrane, the use of expensive SBS copolymer is not justified economically.

Owing to its efficiency and low price, the modifier of a new type presented in this article may contribute to the increase of quality and durability of many popular waterproofing products manufactured with the use of hard bitumen.

\section{REFERENCES}

1. V. Bajpai, K. Tyagi, Synthesis and characterization of imidazolinium surfactants derived from tal-low fatty acids and diethylenetriamine, Research Paper, Vol 110, 935-940, 2008

2. A.D. James, D. Steward, The use of fatty amine derivatives to slow down the age-hardening process in bitumen. Proc. of International Symposium Chemistry of Bitumens, Rzym, T.II, pp. 671, 1991

3. I. Gaweł, M. Kalabińska, J. Piłat, Road asphalt, Wydawnictwo Komunikacji i Łączności, Warszawa 2001

4. P. Radziszewski, M. Kalabińska, J. Piłat, Road materials and asphalt surfaces, Wydawnictwo Poli-techniki Białostockiej, Białystok 1995

5. K. Zieliński, The role of SBS co-polymer in determining the structure and thermomechanical prop-erties of bitumen types used in waterproofing materials, Wydawnictwo Politechniki Poznańskiej, Rozprawy Nr 409, Poznań 2007

6. EN 12593:2004 - Bitumen and bituminous binders. Determination of the Fraass breaking point

7. EN 1427:1999 - Bitumen and bituminous binders. Determination of the softening point - Ring and Ball method

8. EN 12596, Bitumen and bituminous binders - Determination of dynamic viscosity by vacuum capil-lary

9. EN 12607-1:2004 - Bitumen and bituminous binders. Determination of the resistance to hardening under the influence of heat and air - Part 1: RTFOT method

10. K. Zieliński, M. Babiak, Ageing of bitumen contained in waterproofing construction products; Du-rability of Buildings and Structures; Collective work edited by Tomasz Błaszczyński; Dolnośląskie Wydawnictwo Edukacyjne; Wrocław 2012 